\title{
The SADA dental mediation (free and going online)
}

SADJ September 2020, Vol. 75 No. 8 p413 - p414

KC Makhubele

CEO of SADA

The South African Dental Association offers a free and voluntary "complaints resolution" service available to members of the public and Oral Health Care Practitioners $(\mathrm{OHCP})$ when a dispute arises. The service follows a non-adversarial approach and uses the principles of mediation to find a solution or outcome acceptable to both parties.

The structured process is impartial, confidential and without prejudice. The Public and Professionals (includes non-SADA members) have access to a Mediation Process in the event of a dispute. The Dental Mediator will in an ethical and non-partisan manner:

- Mediate in any disputes arising out of the supply of clinical and professional treatment by practitioners to patients.

- Promote and ensure ethical practice by the dental profession.

- Assist with the education of the dental profession with regard to appropriate risk management processes.

\section{About mediation}

Mediation is the most spoken about word in the current national healthcare litigation crisis. It has been advocated by various institutions and even government as a possible solution to drive down the costs of negligence claims and professional indemnity.

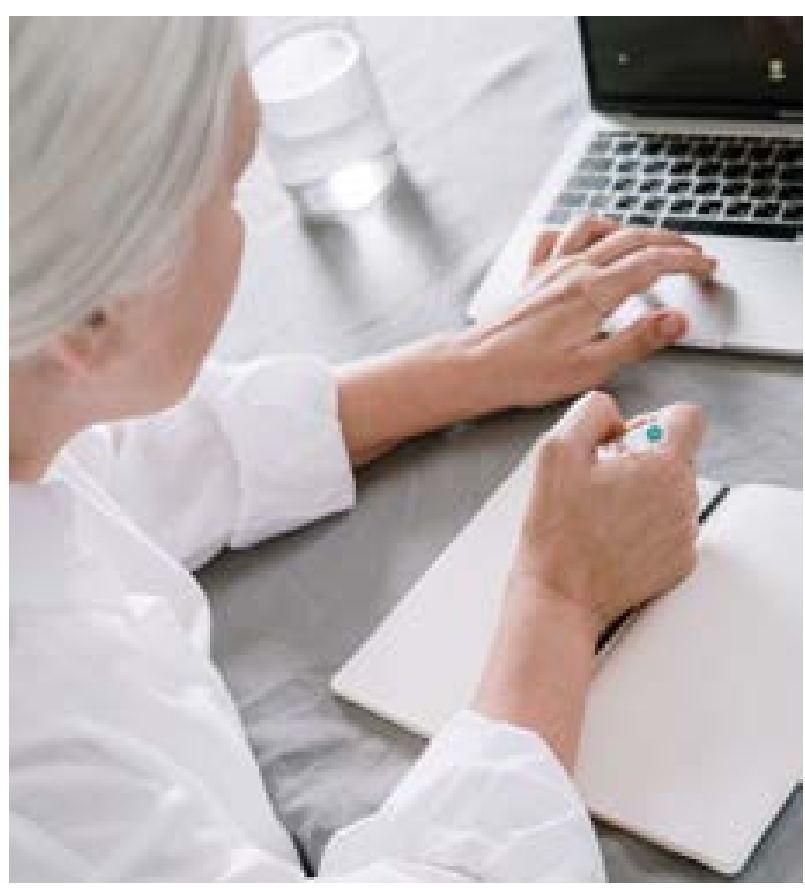

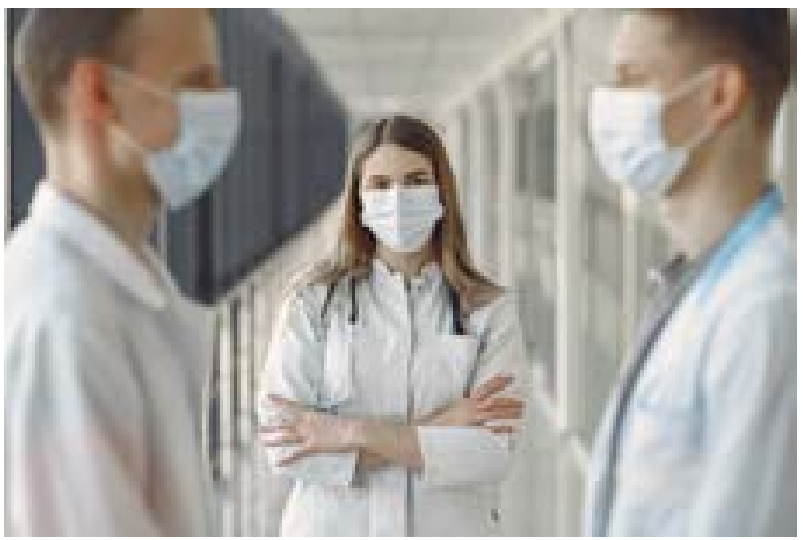

Members will be delighted to know that SADA has been pro-active in this regard by offering a "complaint resolution and mediation service" to its members and their patients since 2013. The service was spearheaded by the late $\operatorname{Dr}$ A Rademeyer in 2013, with $\mathrm{Dr} J$ Barnard taking over the responsibilities two years later.

The service offers a solution for both patients and dentists looking to resolve conflicts and concerns, in a non-adversarial environment, without the involvement of the HPCSA or medical litigation lawyers.

Mediation differs from the process of arbitration, counselling or negotiation in that participants, with the assistance of a neutral person, can systematically isolate issues to develop options, consider alternatives and reach a consensual settlement that will accommodate their unique needs. Currently, all patient complaints received by SADA are automatically referred to the Dental Mediator.

Oral Health Professionals can also contact the Mediator directly for assistance with a patient complaint. Currently, all referrals must be in writing to dentalmediator@sada. co.za. We are very excited that in October 2020, we will be digitising our process making it easy for users to submit their cases online $24 / 7$ and have the ability to check on the progress of their cases.

\section{The mediation service:}

- Is free to Oral Health Professional and their patients; no fees are payable.

- Is voluntary and confidential and participants are free to abandon the process at any time.

- Is impartial and neutral.

- Encourages self-determination by ensuring both par- 
ties recognise their differences and take ownership to resolve the conflict.

- Is not aimed at achieving absolute justice, but to develop options and find the most workable and timeous solution.

Recognising disappointment and identifying solutions are not easy where conflict exists. Some dentists find it extremely difficult to objectively view a complaint and the mediation service offers patients and dentists a solution where a normal complaint handling process does not exist or fails to function effectively.

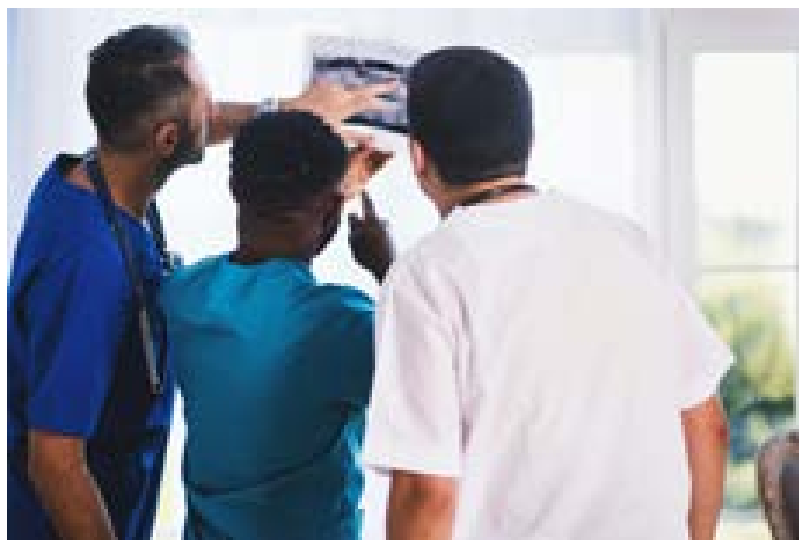

The mediation process follows the following steps:

The Dental Mediator receives a complaint for mediation from either the OHCP or a member of the public.

1. Self-Resolution: Members of the public are encouraged to formalise their compliant and expectations in writing to the treating practitioner before involving any third parties. It is essential that the treating practitioner is aware of the patient's concerns and is given an opportunity to resolve the matters first. The majority of disputes can be resolved through good communication between the member of the dental patient and OHCP.

2. If the "self-resolution" efforts between parties have been unsuccessful and a complaint is subsequently lodged, the Dental Mediator would contact both parties to inform them about the complaint and establish their willingness to participate in a mediation process.

3. If both parties agree to participate in the mediation process, the Mediator will analyse the information at hand. The Mediator may call for further information in any manner he/she deems necessary from any person who, in his opinion, may assist in the mediation to resolve the matter. It may include requesting the $\mathrm{OHCP}$ to respond to the complaint or seek expert advice from his/her indemnifier or other relevant parties such an expert in the field.

4. Once the Dental Mediator is satisfied with the information received, he/she will assist the parties to generate solution options through self-determination to meet the needs and concerns of both parties. Participants are free to leave the mediation process at any time during the process.

5. Once an outcome acceptable to both parties is agreed on, the arrangement will be formalised in an agreement, and the process becomes binding.

6. If the participants, with the help of the mediator, fails to find an outcome acceptable to both parties, the process mediation fails, and parties have to resort to alternative forms of "dispute resolution".

We would like to encourage our members to explore the service, and trust that it will prove to benefit those who make use of it.

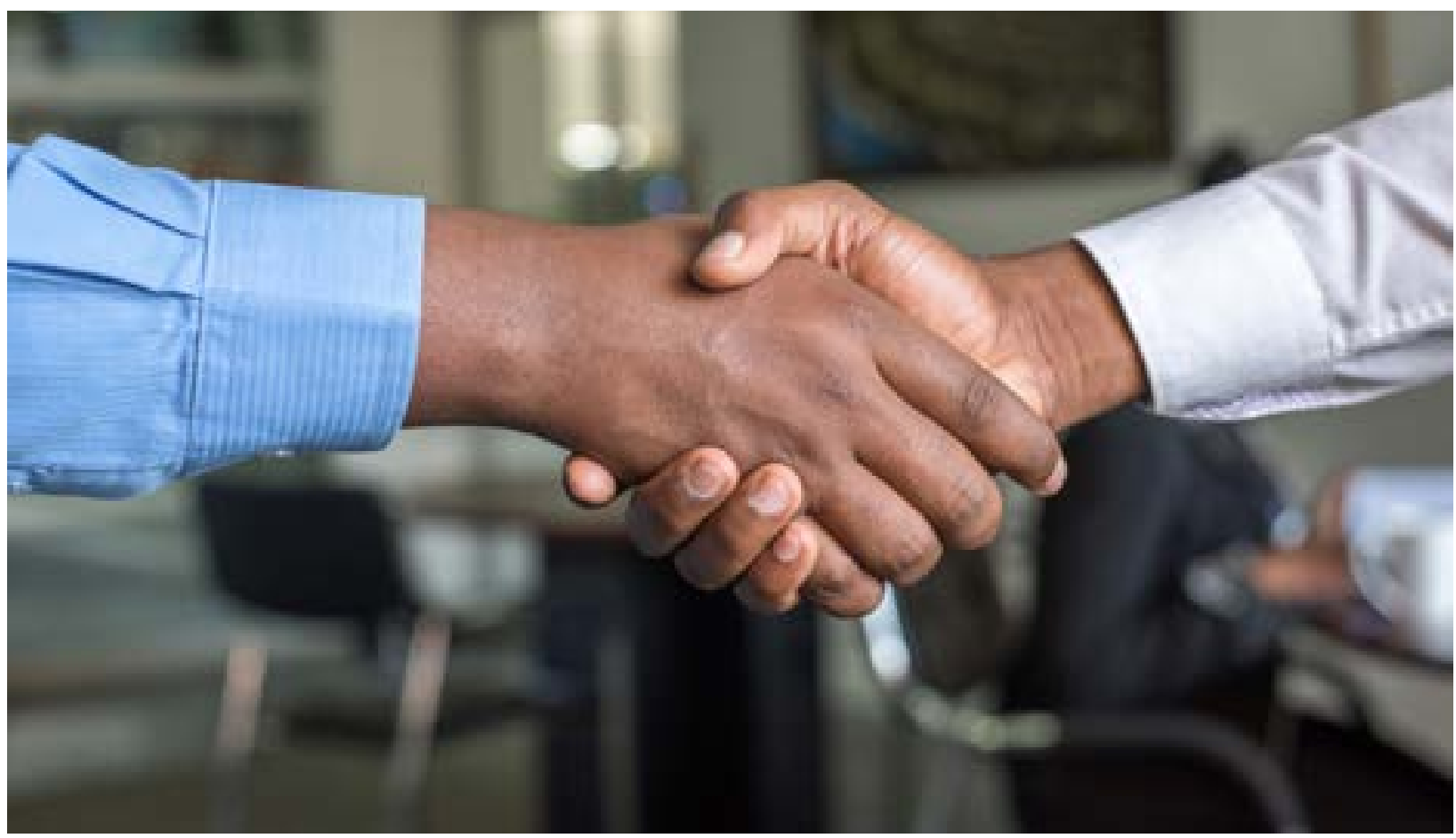

